\title{
Bioremediation of Industrial Effluents by Alkaliphilic Bacteria Isolated from Marine Ecosystems
}

\section{Gaokar Rasika D*}

Department of Microbiology, College of Arts and Science, India

*Corresponding author: Department of Microbiology, College of Arts and Science, P.E.S's R.S.N. College of Arts and Science, Farmagudi, Ponda-Goa, India, Email:

Research article
Volume 3 Issue 1
Received Date: January 01,2018
Published Date: February 01,2018
parth_shriman@yahoo.co.in

\section{Abstract}

Alkaliphilic bacteria are a diverse group of microorganisms capable of surviving at high pH. Industrial pollutants are mainly present in industrial waste effluents which have a high $\mathrm{pH}$. Therefore employing alkaliphiles for bioremediation of toxic compounds present in the industrial waste effluents would be of great help. In this study alkaliphiles were isolated from various marine ecosystems of Goa, West Coast of India. The alkaliphiles were isolated on PPYG medium (Polypeptone Yeast Extract Glucose) medium of $\mathrm{pH}$ 10.5.The buffering capacities of the obligate alkaliphiles obtained from the sediment and water samples were studied. These alkaliphiles were also screened for their ability to degrade a wide range of aromatic compounds and it was observed that most of the alkaliphiles utilized these aromatic compounds especially phenol as sole source of carbon. Further these obligate alkaliphiles also showed an excellent ability to grow on industrial effluents when these effluents were supplemented as sole source of carbon in MSM (Mineral Salt Medium).

Keywords: Alkaliphiles; High pH; Bioremediation; Aromatic compounds; Industrial effluents

Abbreviations: MSM: Mineral Salt Medium; PPYG: Polypeptone Yeast Extract Glucose.

\section{Introduction}

Alkaliphiles or Alkaliphilic: Bacteria are defined as a diverse group of organisms that thrive in highly alkaline environments with optimum $\mathrm{pH}$ for growth being 9 or above. Based on the pH preference alkaliphiles can be classified into two broad categories.

Alkali Tolerant Organisms: That show optimal growth in the $\mathrm{pH}$ range of 7.0-9.0 but grow above $\mathrm{pH} 9.5$. Alkaliphilic Organisms: That show optimal growth between $\mathrm{pH} 10.0$ and 12.0. These organisms can further be subdivided into
- Facultative alkaliphiles: which show optimal growth at pH 10.0 or above but can grow well in neutral pH range and

- Obligate alkaliphiles: which show optimal growth above pH 10.0 but do not grow below pH 9.0 [1].

Marine ecosystems are among the largest of Earth's aquatic ecosystems. They include oceans, salt, marshes, intertidal zones, estuaries, lagoons, mangroves, coral reefs, the deep sea and the sea floor. The marine ecosystems are subject to pollution by various chemicals such as petroleum, hydrocarbons, xenobiotics and heavy metals. Microorganisms capable of degrading most of the constituents of crude oil, xenobiotics are present in the marine environment [2]. Microorgansims with the ability 


\section{Advances in Clinical Toxicology}

to degrade a wide variety of compounds like benzene, phenol, naphthalene, atrazine, nitro aromatics biphenyls, polychlorinated biphenyls (PCB's) and chlorobenzoates have been isolated and characterized at neutral $\mathrm{pH}[3,4]$. But sometimes due to complex structures of the aromatic compounds these substances persist in the environment for a longer time and hence are considered recalcitrant. Although contamination of soils and waters with chemically synthesized phenolic compounds is a serious environmental problem, their remediation may be possible using methods, such as bioremediation. Bioremediation is the metabolic ability of microorganisms to transform or mineralize organic contaminants to less harmful, non -hazardous substances, which are then integrated into natural biogeochemical cycles. The intensity of biodegradation is influenced by several factors, such as nutrients, oxygen, $\mathrm{pH}$ value, composition, concentration and bioavailability of the contaminants, chemical and physical characteristics and the pollution history of the contaminated environment [5]. Study of bioremediation of aromatic compounds at alkaline $\mathrm{pH}$ is important in natural ecosystems where the fate and toxicity of these contaminants is unknown. Further the existence of such microorganisms would promote smooth functioning of the carbon cycle. Use of these microorganisms in removal of aromatic compounds from alkaline and/or industrial wastewater will support the environment concern of industries.

\section{Materials and Methods}

\section{Collection and Analysis of Samples and Enumeration of Alkaliphiles}

Sediment and water samples were collected from marine ecosystems of Goa i.e., Kushawati River and Durbhat mangrove ecosystems, Goa. $\mathrm{pH}$ of the various samples was tested using the $\mathrm{pH}$ paper on the site of collection and using LABINDIA pH analyzer (PHAM) in the laboratory. Neutrophiles were isolated on nutrient agar (pH 7.0) and for isolation of alkaliphiles Polypeptone Yeast extract Glucose PPYG agar pH 10.5 [6]. Haloalkalophiles were isolated on PPYG medium with high pH (10.5) and high salt concentration (25\%). Viable count of alkaliphiles, haloalkaliphiles was determined by plating out water samples and sediment supernatant directly without any dilution on the respective media plates. The plates were incubated for 24-48 hrs at room temperature for neutrophiles, halophiles and alkalophiles and for 7 days for haloalkalophiles, Colonies formed were counted and the total viable count was determined.

\section{Screening of Alkaliphiles for pH Preference}

Predominant isolates from PPYG agar $\mathrm{pH} 10.5$ were replica plated on four sets of PPYG agar plates of $\mathrm{pH} 7,8.5$, 10.5 and 12 to obtain obligate alkaliphiles. The plates were incubated for $48 \mathrm{~h}$ at room temperature and the isolates growing only at $\mathrm{pH} 10.5$ and 12 were selected as obligate.

\section{Determination of Buffering Capacities}

Buffering capacity studies were carried out using methods proposed by Zychlinsky and Martin, Krulwich, et al., Guffanti and Hou [7-9].

Buffering capacity was expressed in terms of nanomoles of $\mathrm{OH}^{-}$ions consumed per mg of cell protein per unit change in $\mathrm{pH}$.

$$
B_{i}=B_{0}-B_{t}
$$

$\mathrm{B}_{0}$ - Whole cell buffering capacity

$\mathrm{B}_{\mathrm{t}}$ - Permeabilised cell buffering capacity

$B_{i}$ - Cytoplasmic cell buffering capacity

As a comparative standard, the buffering capacity of neutrophilic gram negative culture Pseudomonas and gram positive Bacillus grown in PPYG broth $\mathrm{pH} 7$ was determined.

\section{Growth of Alkaliphiles on Various Aromatic Compounds}

The six selected alkaliphilic isolates were screened for their ability to degrade aromatic compounds. The isolates were grown on Mineral Salt Medium (MSM) supplemented with $0.1 \%$ of aromatic compounds such as benzoate, phenol, tyrosine, aniline, cresol, phenylalanine, resorcinol, and quinol as sole source of carbon. The plates were incubated and the results were checked after $48 \mathrm{hrs}$ of incubation.

\section{Screening for Bioremediation of Industrial Waste Effluent}

The obligate alkaliphilic cultures (06) were screened to check their ability of bioremediation of industrial waste effluents arising from an industry using phenol as major raw material. The cultures were streaked on MSM agar containing the effluent ranging from $(0.1 \%-1.0 \%)$ concentration. The plates were incubated at $37^{\circ}$ Cand the growth was monitored after $24 \mathrm{hrs}$ for three to four days. 


\section{Results and Discussions}

\section{Distribution and Total Viable Count of Alkaliphiles}

Polypeptone yeast extract glucose agar $\mathrm{pH} 10.5$ provided a more luxuriant growth of alkaliphilic bacteria. It is well documented that $\mathrm{Na}^{+}$present in PPYG is crucial for the growth of most alkaliphiles [10]. The high $\mathrm{Na}^{+}$ion content of PPYG was perhaps contributing to the growth of obligate alkaliphiles, PPYG medium pH 10.5 was hence selected as the specific medium for further studies. The samples were found to yield the presence of alkaliphilic bacteria and gave high counts on PPYG agar .It was noted that the sediment samples had a higher count on N.A. as compared to water samples. The distribution of alkaliphilic bacteria even in non-alkaline environments has been reported $[11,12]$.

\section{Growth of the Isolates on Media with Different pH}

Twenty predominant isolates were obtained which were further screened for selection of obligate alkaliphiles. These twenty isolates were plated on PPYG agar of $\mathrm{pH} 6,8.5,10.5$ and 12 . The isolates growing only at pH 10.5 and 12 were selected to be obligate alkaliphiles.

\section{Buffering Capacities of Obligate Alkaliphiles}

In this study, the cytoplasmic buffering capacities of the six obligately alkaliphilic isolates and two neutrophilic isolates were determined. It was interesting to note that the amount of $0.05 \mathrm{M} \mathrm{KOH}$ required by the alkaliphilic isolates ranged from $150 \mu$ l to $1000 \mu \mathrm{l}$ for change of $1 \mathrm{pH}$ unit Figure $1 \mathrm{a} \& \mathrm{~b}$.

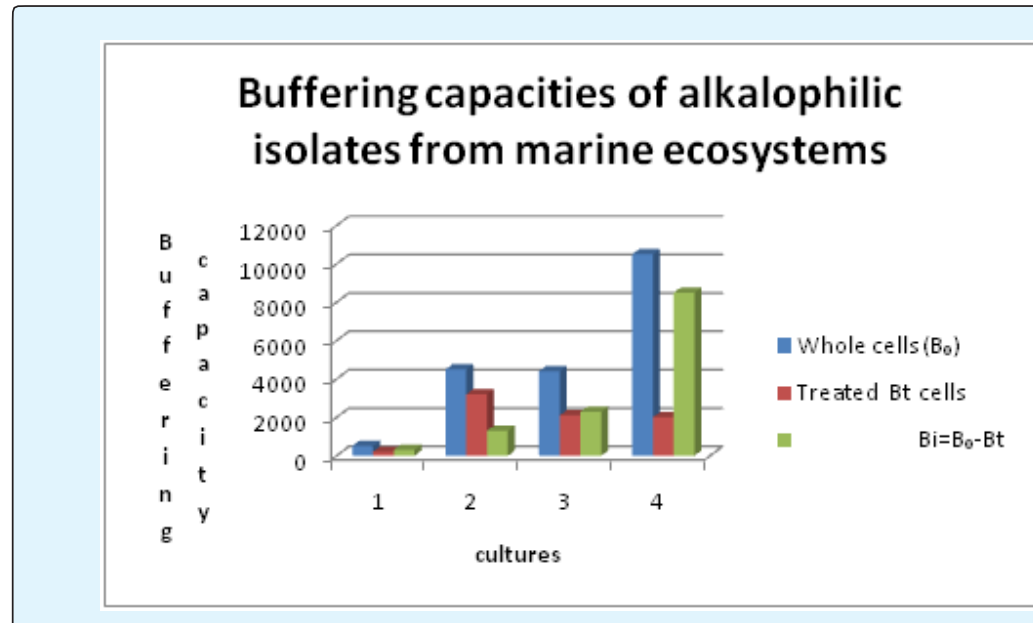

Figure 1a: Buffering capacities with cultures (1) Bacillus (2) FA7 (3) WA3 (4) KWS.

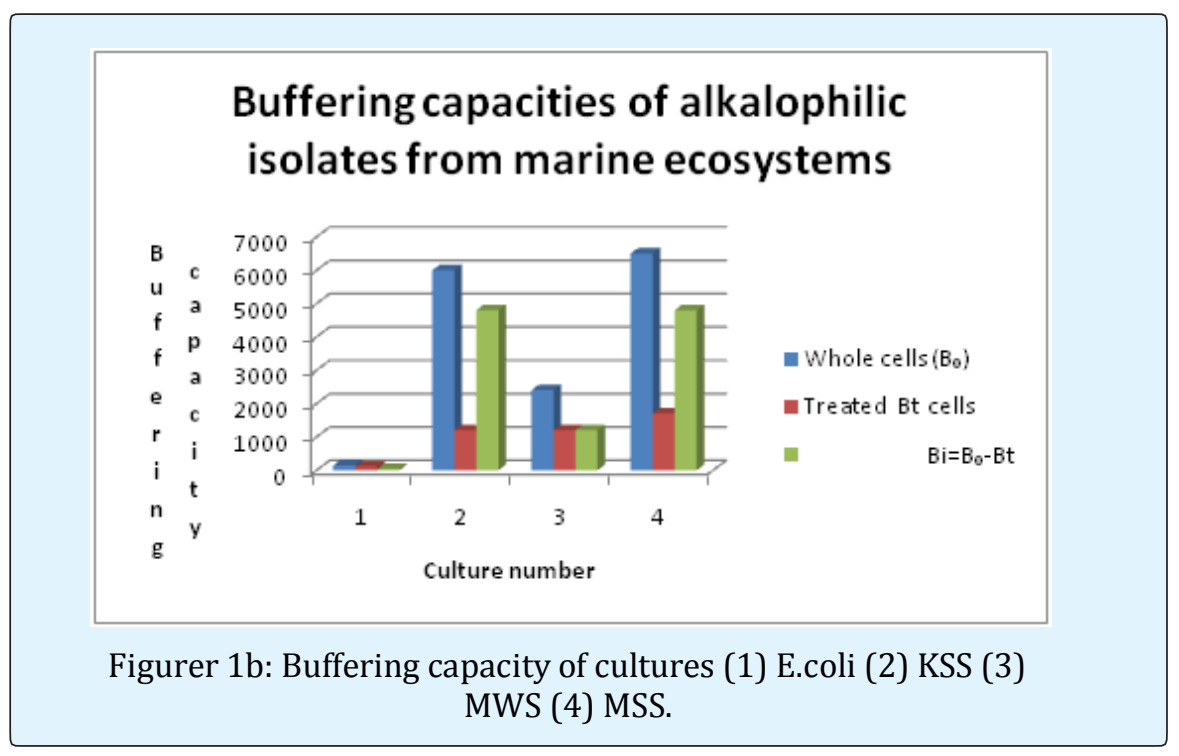




\section{Growth of Alkaliphiles on Aromatic Compounds}

All these isolates grew luxuriantly when supplemented with benzoate, phenol and tyrosine Table 1 whereas the isolates were not capable of utilizing aniline, cresol and other phenolic compounds such as resorcinol and quinol Table 1. However none of the isolates grew when supplemented with resorcinol, quinol, aniline and parachloroaniline as sole source of carbon Table 1. The substrate concentration at which the cultures exhibited good growth was selected as the optimum concentration of the substrate for the culture I.e, $0.3 \%$ benzoate, $0.2 \%$. Phenol and $0.2 \%$ tyrosine. Ability of the cultures to tolerate up to $0.2 \%$ phenol is an unique property exhibited which can be used in bioremediation of industrial effluents.

\begin{tabular}{|c|c|c|c|c|c|c|c|c|}
\hline \multirow{2}{*}{ Isolates } & \multicolumn{7}{|c|}{ Aromatic Compounds } \\
\cline { 2 - 9 } & Benzoate & Phenol & Tyrosine & Aniline & Phenyl-alanine & Resinol & Cresol & Quinol \\
\hline FA7 & + & + & + & - & - & - & - & - \\
\hline WA3 & + & + & + & - & - & - & - & - \\
\hline KWS & + & + & + & - & - & - & - & - \\
\hline KSS & + & + & + & - & - & - & - & - \\
\hline MWS & + & + & + & - & - & - & - & - \\
\hline MSS & + & + & + & - & - & - & - & - \\
\hline
\end{tabular}

Key: + Degree of growth, - No growth

Table 1: Growth of isolates on different aromatic compounds.

\section{Screening for Bioremediation of Industrial Waste Effluents}

The alkaliphilic bacteria which were screened for ability of bioremediation of industrial waste effluents showed that these isolates exhibited excellent growth up to a concentration of $0.2 \%$ of the industrial effluent Figure 2 indicating that these isolates can be exploited as excellent candidates for bioremediation of industrial effluents. Similar studies using alkaliphilic bacteria for bioremediation of phenol using industrial effluents have been reported [13-18].

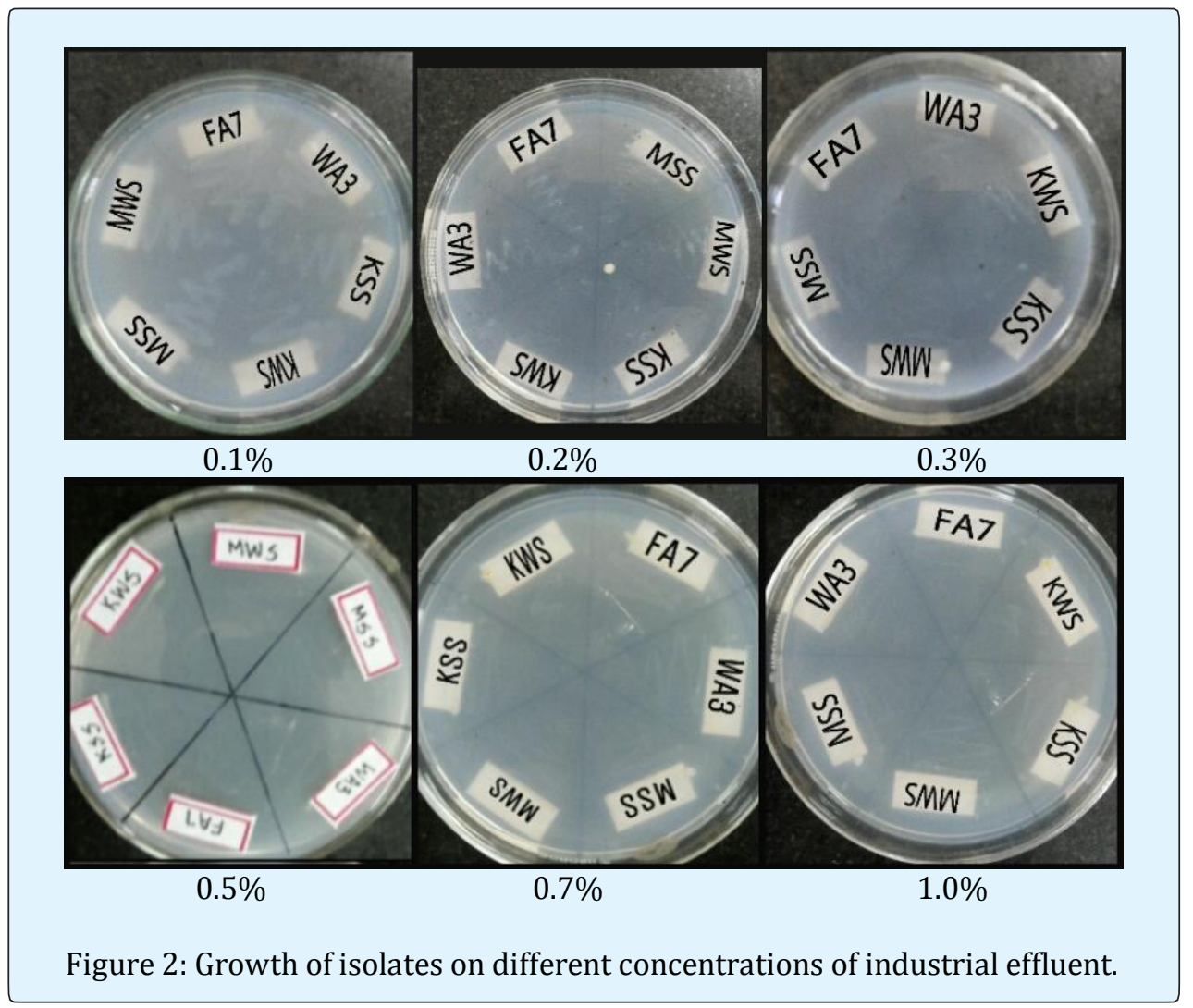




\section{Conclusions}

From the present study the alkaliphiles from marine ecosystems of Goa were studied with respect to biodiversity, buffering capacities and their ability to biodegrade aromatic compounds under alkaline conditions. Although contamination of waters with chemically synthesized phenolic compounds is a serious environmental problem, their remediation may be possible using bioremediation. Since some of the phenolbearing industrial waste waters are alkaline in nature, it was thought worthwhile to explore the use of alkaliphilic bacteria for the removal of phenol.

\section{Acknowledgement}

The author wish to extend gratitude to the Principal Dr. AS Dinge for providing the necessary facilities and to Dr. Sunita Borkar and Miss Neha Prabhu for their cooperation in the experimental work.

\section{References}

1. Krulwich TA, Guffanti AA (1983) Physiology of acidophilic and alkalophilic bacteria. Adv Microbial Physiol 24: 173-214.

2. Karunasagar (2001) Bioremediation in the marine environment. Biotechnology 9.

3. Sangodkar UMX, Aldrich TL, Haugland RA, Janson J, Rathmol RK, et al. (1989) Molecular basis of biodegradation of chloroaromatic compounds. Acta Biotechnol 9(4): 301-316.

4. Dickel D, Haug W, Knackmus HJ (1993) Biodegradation of nitrobenzene by a sequential anaerobic-aerobic process. Biodegradation 4(3): 187194.

5. Zchendir AJ, Bouwer EJ (1993) Bioremediation of organic compounds: microbial metabolism to work. Trends Biotechnol 11(8): 360-367.

6. Gee TM, Lund BM, Metcalf G, Peel TL (1980) Properties of a new group of alkalophilic bacteria. J Gen Microbiol 117: 9-17.

7. Zychlinsky E, Matin A (1983) Cytoplasmic pH homeostasis is an acidophilic bacterium Thio bacillus acidophius. J Bacteriol 156(3): 1352-1355.
8. Krulwich AT, Agus R, Schneier M, Guffanti AA (1985) Buffering capacity of Bacilli that grow at different $\mathrm{pH}$ ranges. J Bacteriol 162(2): 768-772.

9. Guffanti AA, Hou E (1987) The effect of $\mathrm{pH}$ on the passive proton conductance of Bacillus acidocaldarius. FEMS Microbiol Lett 41(3): 275-278.

10. Krulwich TA, Guffanti AA, Bomstein RF, Hoffstein J (1982) A sodium requirement for growth, solute transport and $\mathrm{pH}$ homeostasis in Bacillus firmus $\mathrm{RAB} \mathrm{J}$ Biol Chem 257(4): 1885-1889.

11. Borkar S, Nagarsekar Y, Bhosle S (2003) Alkaliphilic and alkali tolerant organisms from an agrochemical factory. Asian Jr of Microbiol Biotech Env Sci 5(2): 187-191.

12. Desai RS, Krishnamurthy NK, Mavinkurve S, Bhosle S (2004) Alkaliphiles in estuarine mangrove regions of Goa,(central west coast of India). Indian journal of marine sciences 33(2): 177-180.

13. Tambekar DH, Bhorse PS, Gadakh PV (2012) Biodegradation of Phenol by native microorganisms isolated from Lonar Lake in Maharashtra State (India). International Journal of Life Sciences and Pharma Research 2(4): 26-30.

14. Tambekar DH, Tale SD, Borkar PR (2013) Bioremediation of phenol by Haloalkaliphilic microorganisms isolated from Lonar Lake. International Journal of Sciences, Environment and Technology 2(3): 434-441.

15. Gilmour R, Krulwich TA (1996) Purification and characterization of the succinate dehydrogenase complex and CO-reactive b-type cytochromes from the facultative alkaliphile Bacillus firmus OF4. Biochim Biophys Acta 1276(1): 57-63.

16. Horikoshi K (1991) Microorganisms in alkaline environments. VCH Publishers, New York.

17. Lewis RJ, Kaback E, Krulwich TA (1982) Pleiotropic properties of mutations to non-alkalophily in Bacillus alkalophilus. J Gen Microbiol 128: 427-430.

18. Ellis BML (2000) Environmental biotechnology informatics. Curr Opin Biotechnol 11(3): 232-235. 